\title{
Pain after posterolateral versus nerve-sparing thoracotomy: A randomized trial
}

Sabita Jiwnani, MCh, MRCS, ${ }^{a}$ Priya Ranganathan, MD, ${ }^{\mathrm{b}}$ Vijaya Patil, MD, ${ }^{\mathrm{b}}$

Vandana Agarwal, MD, FRCA, ${ }^{\mathrm{b}}$ George Karimundackal, MCh, MRCS, ${ }^{\mathrm{a}}$ and C. S. Pramesh, MS, FRCS ${ }^{\mathrm{a}}$

\section{ABSTRACT}

Objectives: Post-thoracotomy pain leads to patient discomfort, pulmonary complications, and increased analgesic use. Intercostal nerve injury during thoracotomy or its entrapment during closure can contribute to post-thoracotomy pain. We hypothesized that a modified technique of posterolateral thoracotomy and closure, preserving the intercostal neurovascular bundle, would reduce acute and chronic post-thoracotomy pain.

Methods: We randomized 90 patients undergoing posterolateral thoracotomy for pulmonary resection at a tertiary level oncology center to standard posterolateral (control arm) or modified nerve-sparing thoracotomy. All patients received morphine via patient-controlled analgesia pumps. The primary outcome was the worst postoperative pain score in the first 3 postoperative days. Secondary outcomes included the average pain score and analgesic requirements in the first 3 postoperative days and the incidence of post-thoracotomy pain 6 months after surgery.

Results: No significant differences were seen between the groups in acute or chronic post-thoracotomy measured by the numeric rating scale. There was no difference seen in the worst (mean) postoperative pain scores (3.71 vs 3.83, difference $0.12 ; 99 \%$ confidence interval $[\mathrm{CI}],-0.7$ to $+0.9 ; P=.7$ ), average (mean) pain scores in the first 3 postoperative days (1.77 vs 1.85 , difference $0.08 ; 99 \% \mathrm{CI},-0.4$ to $+0.6 ; P=.69)$, mean consumption of morphine $(\mathrm{mg} / \mathrm{kg})(1.45$ vs 1.40 , difference $-0.05 ; 99 \% \mathrm{CI},-0.4$ to $+0.3 ; P=.73)$, or incidence of chronic postoperative pain $(37.8 \%$ vs $40 \%$, difference $4.9 \%$; $99 \%$ CI, -22.8 to $+30.7 \% ; P=.73)$.

Conclusions: The modified nerve-sparing thoracotomy technique does not reduce post-thoracotomy pain compared with standard posterolateral thoracotomy. (J Thorac Cardiovasc Surg 2019;157:380-6)

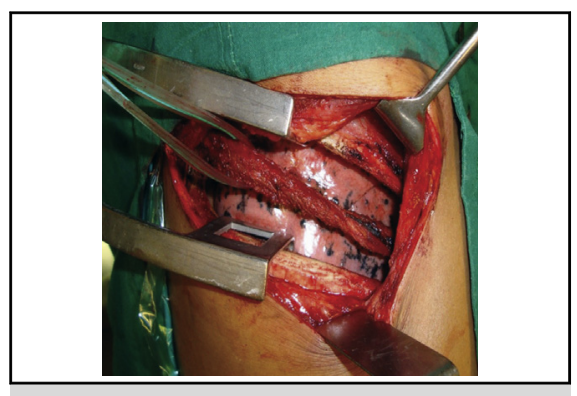

Protecting the neurovascular pedicle by dissecting the intercostal muscle flap.

\section{Central Message}

Protection of the intercostal nerve alone during thoracotomy does not affect acute or chronic PTP, which is likely to be multifactorial

\section{Perspective}

PTP leads to patient discomfort, pulmonary complications, and increased analgesic use. We hypothesized that protecting the intercostal neurovascular pedicle during thoracotomy and closure could decrease PTP. Our study results show no effect on PTP with a nerve-sparing strategy. PTP is multifactorial, and multidisciplinary management using a combination of techniques is needed.

See Editorial Commentary page 387.

See Editorial page 376.
From the a Division of Thoracic Surgery, Department of Surgical Oncology and ${ }^{b}$ Department of Anaesthesiology, Critical Care and Pain, Tata Memorial Centre, Mumbai, India.

The study was funded by an intramural research grant from the Department of Atomic Energy Clinical Trials Centre, Tata Memorial Centre, Mumbai, India.

Read at the World Conference on Lung Cancer, October 27-30, 2013, Sydney, Australia.

Clinical Trial Registry Number: The trial was registered with the Clinical Trials Registry of India (CTRI/2010/091/000583). Date and number of Institutional Review Board approval: April 29, 2010; Project No. 749.

Received for publication Jan 10, 2018; revisions received June 19, 2018; accepted for publication July 3, 2018; available ahead of print Sept 6, 2018.

Address for reprints: C.S. Pramesh, MS, FRCS, Division of Thoracic Surgery, Department of Surgical Oncology, Tata Memorial Hospital, Parel, Mumbai 400012, India (E-mail: prameshcs@tmc.gov.in).

0022-5223/\$36.00

Copyright (c) 2018 by The American Association for Thoracic Surgery

https://doi.org/10.1016/j.jtcvs.2018.07.033
Posterolateral thoracotomy has been the workhorse incision for the thoracic surgeon for several decades. ${ }^{1}$ Although it provides excellent access to the thoracic cavity for general and oncologic thoracic resections, ${ }^{2}$ the morbidity associated with the incision is considerable. ${ }^{3}$ Postoperative pain is extremely common after a posterolateral thoracotomy. ${ }^{4}$ Acute post-thoracotomy pain (PTP) can be disabling and

Scanning this QR code will take you to a supplemental video for the article.

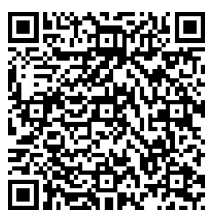



Abbreviations and Acronyms
$\mathrm{CI}=$ confidence interval
PCA $=$ patient-controlled analgesia
PTP $=$ post-thoracotomy pain
VATS $=$ video-assisted thoracoscopic surgery

lead to complications due to splinting of the chest wall leading to decreased postoperative respiratory efforts, retention of secretions, and pulmonary complications. ${ }^{5}$ The International Association for the Study of Pain definition of chronic pain after thoracotomy is "Pain that recurs or persists along a thoracotomy scar at least 2 months following surgical procedure." ${ }^{6}$ The reported prevalence of chronic PTP varies widely, ${ }^{7}$ from $11 \%$ to $80 \%$ with approximately $50 \%$ reporting pain even 1 year after surgery. ${ }^{4}$ This pain can be severe in intensity, is distressing to the patient, is difficult to treat, decreases quality of life, and can interfere with respiratory function. ${ }^{5}$

Considerable efforts have been directed toward reducing the intensity of acute PTP, based on the assumption that acute pain is a predictive factor for chronic pain. ${ }^{8}$ Because PTP shows many neuropathic components, ${ }^{4}$ it is likely that intercostal nerve injury plays a key role in the development of this condition. This concept has been reinforced by neurophysiologic studies that demonstrate an association between intercostal nerve damage and the intensity of PTP. Studies ${ }^{9,10}$ have shown significant intercostal nerve damage with resultant nerve conduction defects after thoracotomy; also, impaired nerve conduction was seen more often in those having PTP compared with those without pain.

Animal studies in rat models ${ }^{11}$ show a clear association between the duration of rib retraction with subsequent allodynia with histopathologic examination showing demyelination of the intercostal nerve, establishing the role of axonal damage in producing neuropathic symptoms.

One of the theories for causation of PTP is related to the operative technique of thoracotomy and closure. ${ }^{12}$ While opening the thorax and using the self-retaining thoracic retractor, the vertical blade of the retractor causes pressure on the intercostal nerve of the rib above; likewise, during closure of the thoracotomy, pericostal sutures placed in the intercostal space below causes pressure on the intercostal neurovascular bundle of the rib below. ${ }^{12}$ This pressure on these 2 intercostal nerves is considered one of the major mechanisms underlying PTP. ${ }^{4,12}$ Previous studies have evaluated various modifications of surgical techniques (including our proposed technique) to minimize intercostal nerve damage during thoracotomy with varying results. ${ }^{13-17}$

We aimed to compare PTP in patients undergoing standard posterolateral thoracotomy (without preservation of the intercostal neurovascular bundle and using pericostal sutures) versus a modified nerve-sparing technique (preserving the intercostal neurovascular bundle and using intracostal sutures).

\section{PATIENTS AND METHODS}

We performed the study over a 2-year period in a tertiary-level oncology center with a high volume of thoracic surgery. Ethics approval was obtained from the Institutional Review Board before recruitment, and the study was conducted in accordance with the principles of the Declaration of Helsinki. Written informed consent was obtained from all participants. The study was performed per published guidelines (International Committee of Medical Journal Editors) and is reported in accordance with the Consolidated Standards of Reporting Trials statement. The trial was registered with the Clinical Trials Registry of India (CTRI/2010/091/000583).

\section{Trial Design and Participants}

All patients aged 18 to 75 years with an Eastern Cooperative Oncology Group performance status of 0 or 1 and American Society of Anesthesiologists grade I or II undergoing lung resection for primary lung cancer or metastases were eligible for the study. Those with previous thoracotomy or additional incisions (besides thoracotomy); receiving narcotic analgesics, anti-inflammatory drugs, and medications for neuropathic pain (anticonvulsants, gabapentin, and analogues, amytriptyline); who were unreliable for follow-up; or with a history of previous thoracic radiotherapy, chest wall involvement, contraindication to fentanyl, morphine, paracetamol, or diclofenac were excluded. All patients were counseled regarding options for postoperative analgesia, and those not willing to use or unable to comprehend the use of patient-controlled analgesia (PCA) were excluded.

\section{Randomization}

Patients were randomized (1:1) just before thoracotomy in the operating room. Randomization was done using computer-generated permuted blocks of random numbers, and allocation concealment was ensured by telephonic randomization from a central Clinical Research Secretariat. Although the surgeon could not be blinded, both the patient and the clinician assessing postoperative pain were blinded to the type of thoracotomy, as were the ward nurses, data collectors, and analysts. The type of thoracotomy performed (nerve-sparing/conventional posterolateral) was not mentioned in the surgical notes but was maintained in a separate research database at the clinical trials unit.

\section{Interventions}

Surgery: Posterolateral thoracotomy (Figure 1) was performed at the superior border of the sixth rib, in the fifth intercostal space, through the posterior half of the latissimus dorsi and preserving the entire serratus anterior muscle, without cutting or shingling the rib intentionally. In the control group (standard posterolateral thoracotomy), no attempt was made to dissect or preserve the intercostal bundle, and pericostal sutures were taken during closure of the thoracotomy. In the modified thoracotomy group, the fifth intercostal neurovascular bundle was carefully dissected along with the intercostal muscle by harvesting it off the inferior edge of the fifth rib using diathermy (fulgurate, blend mode) on a subperiosteal plane. The muscle was deflected downward from under the inferior surface of the rib (Figure 2) and taken off from almost the entire rib, kept intact, and suspended with the help of a soft drain during the surgery (Figure 3 ) to avoid the intercostal muscle flap being crushed under the chest retractor. During closure of the thoracotomy wound, holes were drilled in the inferior (sixth) rib for the passage of suture material (Figure 4) to avoid damage to the sixth intercostal nerve. Sutures to close the thoracotomy were taken through holes drilled in the inferior (sixth) rib and through the lower edge of the fourth intercostal space 


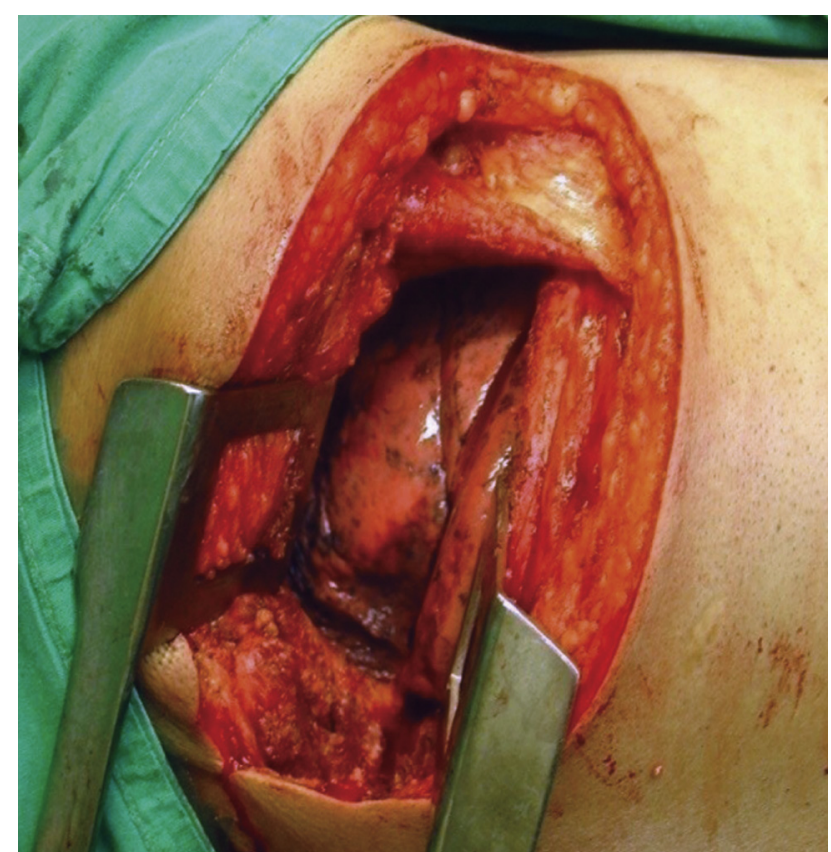

FIGURE 1. Standard posterolateral thoracotomy with rib retractor.

(pericostal) as the neurovascular bundle traverses along the upper edge of the fourth intercostal space (Figure 4). The video of the technique is available as supplementary material (Video 1).

Anesthesia and analgesia: Analgesia management was standardized and identical in both groups. Patients received intravenous fentanyl and morphine intraoperatively titrated to clinical end points at the discretion of the operating room anesthetist.

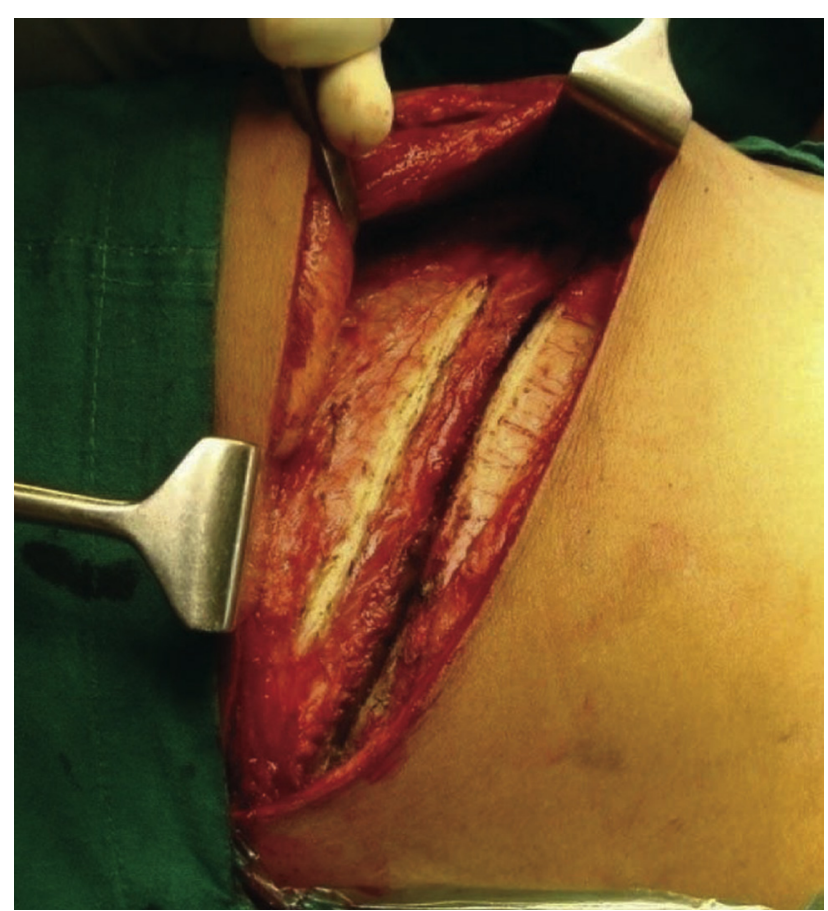

FIGURE 2. Intercostal muscle flap deflected downward from the edge of the upper rib.

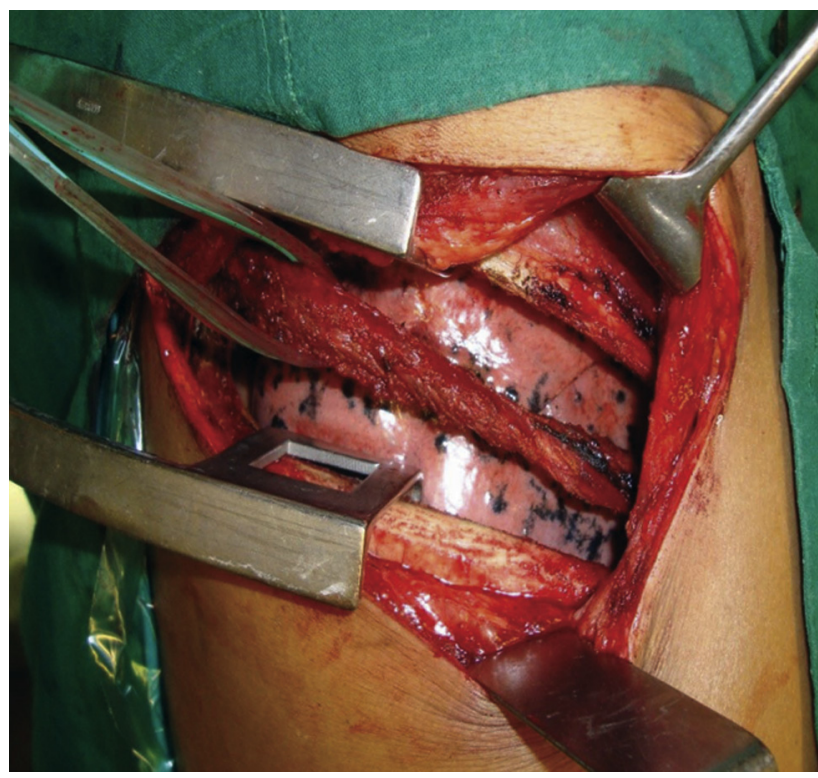

FIGURE 3. Dissected intercostal muscle flap with the neurovascular pedicle.

Additional analgesia in the form of diclofenac ( $1 \mathrm{mg}$ per $\mathrm{kg}$, maximum $75 \mathrm{mg}$ ) and paracetamol (20 mg per $\mathrm{kg}$, maximum $1000 \mathrm{mg}$ ) were given just before thoracotomy closure. Postoperatively, patients in both groups received oral round-the-clock paracetamol and diclofenac adjusted to their body weight along with intravenous PCA using morphine boluses. The PCA pump was disconnected at the end of 3 postoperative days or earlier if the pain score was consistently less than $3 / 10$ on a numeric rating scale for 4 hours without the use of PCA. The total morphine requirement was recorded for all patients. A uniform and consistent policy was followed for removal of chest drains; intraoperatively, a single $24 \mathrm{~F}$ polyvinylchloride drain was introduced; removal of the drain was done when the following criteria were met: clear/serous output less than $5 \mathrm{~mL} / \mathrm{kg}$ body weight and no air leak on active breathing.

\section{Outcomes}

A hospital research nurse (who was blinded to the randomization allocation) recorded pain using the Numeric Rating Scale 0 to 10. Patients in

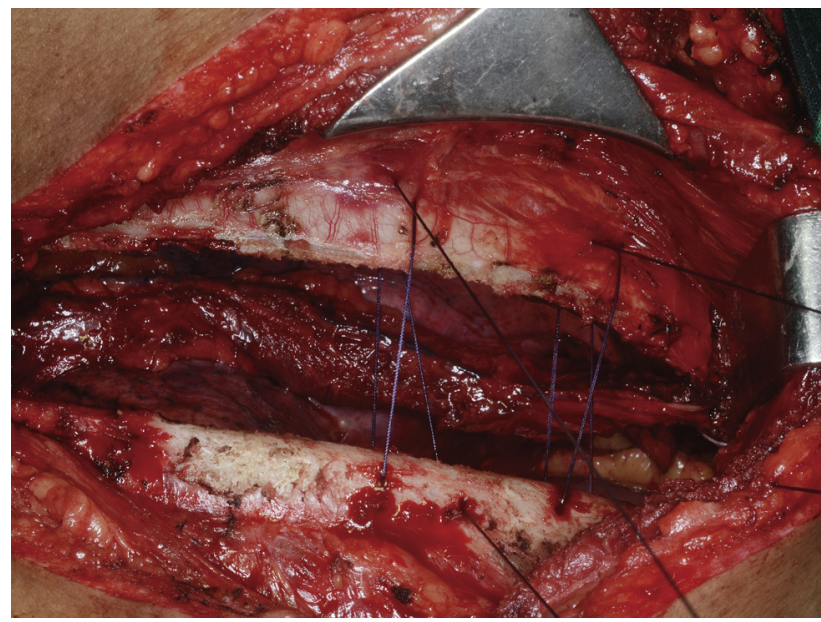

FIGURE 4. Pericostal sutures for closure of thoracotomy wound. 


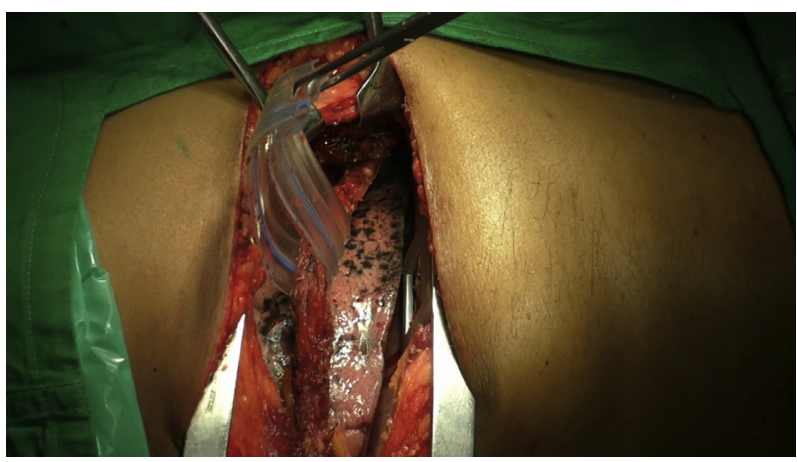

VIDEO 1. Operative video demonstrating the nerve-sparing thoracotomy technique. Video available at: https://www.jtcvs.org/article/S0022-5223 (18)32009-9/fulltext.

both arms were asked about the worst and average pain experienced in the last 24 hours, and the score was recorded on postoperative days 1, 2, and 3 and between days 10 and 14, when the patient followed up at the hospital for suture removal. We recorded analgesic consumption ( $\mathrm{mg} / \mathrm{kg}$ morphine) in the first 3 days for all patients. We assessed chronic pain at 6-month follow-up using a standard questionnaire. ${ }^{18}$ We decided on these timepoints for pain assessment as the maximum postoperative pain occurs in the first 3 days after thoracotomy, and we wanted to restrict the number of between-group comparisons to a reasonable number.

We compared a variety of pain-related outcomes between the 2 arms, the primary outcome being the worst postoperative pain score (mean of worst pain daily) in the first 3 postoperative days. The secondary outcomes were average postoperative pain score (mean of first 3 postoperative days), analgesic requirement (intravenous morphine) in the first 3 postoperative days, and the incidence of chronic PTP (measured at 6 months). The study was independently powered to answer each of these questions by a very conservative adjustment for multiple comparisons (Bonferroni correction).

\section{Statistical Analysis}

Assuming 99\% confidence and 95\% power, we required 37 patients in each arm to detect a reduction in mean pain score by 1 point in the nerve-sparing thoracotomy group (common standard deviation of 2). Using the Bonferroni correction, we calculated an alpha of 0.01 to adjust for multiple comparisons (for the different end points). Accounting for perioperative mortality, protocol deviations, and loss to follow-up, we aimed to accrue 45 patients in each arm. Statistical analysis was done on an intention-to-treat basis. We used the Student $t$ test to compare numeric data and the chi-square test for categoric data. All $P$ values were 2 sided.

\section{RESULTS}

Ninety patients were randomized to conventional or nerve-sparing thoracotomy. The trial profile is shown in Figure 5, and the baseline demographic and clinical characteristics of patients are shown in Table 1.

\section{Baseline Characteristics}

Both the groups were well matched with respect to baseline characteristics and the surgery performed (Table 1).

\section{Assessment of Pain}

The worst and average pain in the first 3 postoperative days were similar in the 2 groups (Figures 6 and 7). Most

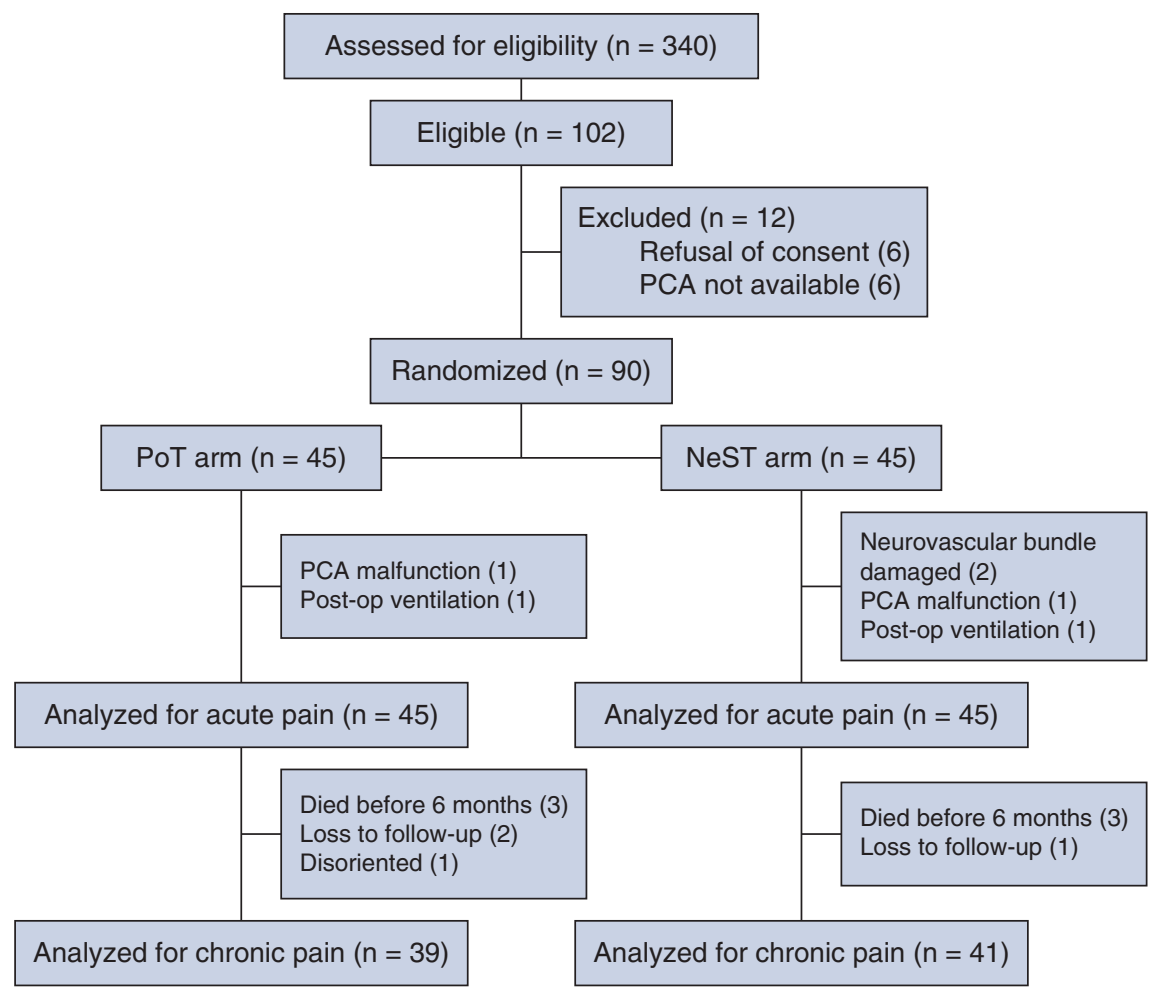

FIGURE 5. Consolidated Standards of Reporting Trials diagram showing participant flow in the trial. PoT, Posterolateral; NeST, nerve sparing; $P C A$, patient-controlled analgesia; Post-op, postoperative. 
TABLE 1. Baseline characteristics

\begin{tabular}{lcc}
\hline Baseline characteristics & $\begin{array}{c}\text { Posterolateral } \\
(\mathbf{n}=\mathbf{4 5})\end{array}$ & $\begin{array}{c}\text { Nerve-sparing } \\
(\mathbf{n}=\mathbf{4 5})\end{array}$ \\
\hline Gender $(\mathrm{M} / \mathrm{F})$ & $33(73 \%) / 12(27 \%)$ & $30(67 \%) / 15(33 \%)$ \\
Age, $\mathrm{y}^{*}$ & $40.7( \pm 14.9)$ & $43.1( \pm 16.8)$ \\
Weight, kg* & $58( \pm 11.7)$ & $57.9( \pm 14.9)$ \\
Body mass index & $23.0( \pm 6.7)$ & $21.7( \pm 4.0)$ \\
$\begin{array}{l}\text { Type of surgery } \\
\text { Lobectomy }\end{array}$ & $22(49 \%)$ & $29(64 \%)$ \\
$\quad \begin{array}{l}\text { Pneumonectomy } \\
\text { Metastatectomy }\end{array}$ & $16(35 \%)$ & $11(24 \%)$ \\
$\quad$ Exploratory & $7(16 \%)$ & $2(8 \%)$ \\
$\quad$ thoracotomy & 0 & $138(90-225)$ \\
Operative duration (min) $\dagger$ & $190(103-263)$ & $8(18 \%)$ \\
No. of patients with & $11(24 \%)$ & \\
$\quad$ rib injury & & \\
\hline$M$, Male; $F$, female. $*$ Data are expressed as mean (with standard deviation) for contin- \\
uous data and actual numbers (with percentages) for categoric data. $\dagger$ Median with in- \\
terquartile range.
\end{tabular}

patients $(38 / 45 ; 84 \%$ in the posterolateral group and $38 / 45$; $84 \%$ in the nerve-sparing group) had maximum pain recorded on the first postoperative day. The groups were also comparable with respect to the amount of morphine required in the first 3 postoperative days (Table 2). A considerable number of patients reported chronic PTP at the 6-month follow-up in both the groups $(46 \%$ in the posterolateral thoracotomy group and $41 \%$ in the nervesparing group), but this was not significantly different.

\section{Adverse Events}

There was no difference in adverse events between patients undergoing the conventional posterolateral and the nerve-sparing thoracotomy (Table 3). Similar numbers of patients had pulmonary complications (posterolateral, $\mathrm{n}=4 ; 1$ each had atelectasis, consolidation, pneumonia,

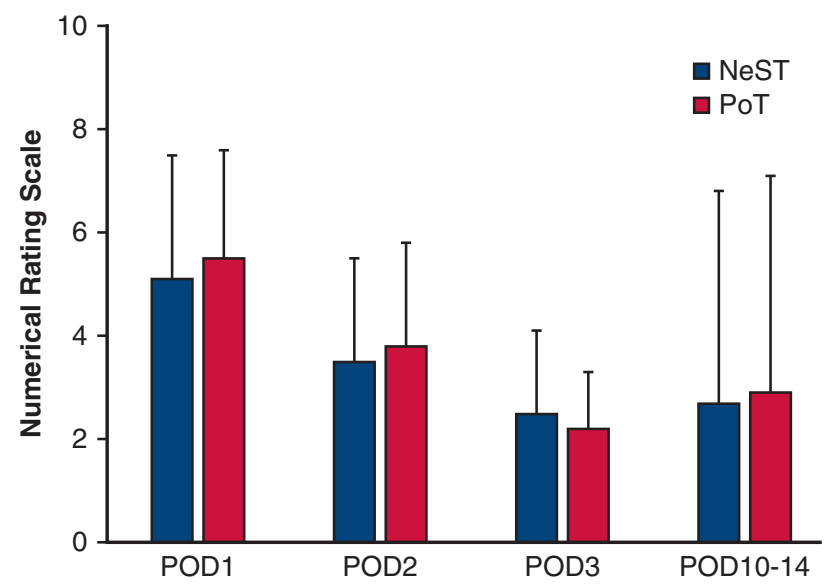

FIGURE 6. Box and whiskers plot of mean maximum pain levels on days 1, 2, 3, and 10 to 14. NeST, Nerve sparing; PoT, posterolateral; POD, postoperative day.

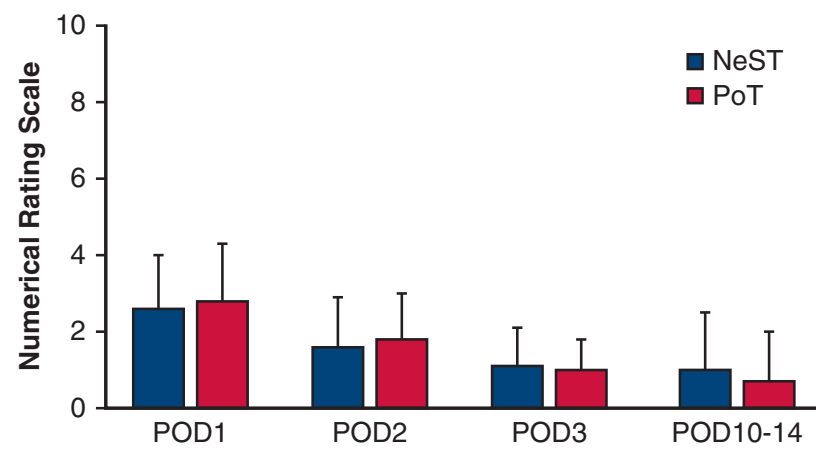

FIGURE 7. Box and whiskers plot of mean average pain levels on days 1 , 2, 3, and 10 to 14 . NeST, Nerve sparing; PoT, posterolateral; POD, postoperative day.

and prolonged air leak; nerve-sparing, $\mathrm{n}=3 ; 2$ had bronchopneumonia and 1 had consolidation).

The modified "nerve-sparing" thoracotomy did not reduce acute or chronic PTP in this double-blind randomized trial. All parameters studied, including the intensity of pain, need for analgesics, and incidence of chronic PTP, were similar in the nerve-sparing group compared with the conventional posterolateral thoracotomy group.

Surgical modifications to eliminate or decrease PTP have included the use of muscle-sparing thoracotomy, ${ }^{18-22}$ preservation of the intercostal nerve/neuromuscular bundle, ${ }^{13-17}$ and increasing use of minimally invasive surgery. ${ }^{23-28}$ Although video-assisted thoracoscopic surgery (VATS) has considerable promise in reducing postoperative pain in thoracic surgery, several factors, predominantly related to the disease, expertise, and availability of infrastructure makes conventional thoracotomy still the most widely used incision in general as well as oncologic thoracic surgery worldwide. ${ }^{29,30}$ Moreover, adoption of VATS has been variable globally, and few centers have a high proportion of VATS compared with open procedures. $^{30}$

Intraoperative factors such as rib retraction and trauma to the intercostal nerves have been postulated to be potential causes of PTP. ${ }^{9}$ Previous studies have compared techniques to minimize nerve damage during thoracotomy.

Cerfolio and colleagues ${ }^{16}$ compared intracostal with pericostal sutures in 280 patients and found lower acute and chronic pain scores in the intracostal group. The same hypothesis was tested by Bayram and colleagues ${ }^{31}$ in a prospective randomized trial involving 60 patients. They found lower acute pain scores and analgesic consumption in the intracostal group; however, the incidence of chronic pain was not estimated. Two randomized studies by Cerfolio and colleagues ${ }^{14,16}$ evaluated the impact of creating an intercostal muscle flap on chronic pain; long-term pain was less in the group with the intercostal flap compared with control. However, both these studies had certain 
TABLE 2. Pain scores in posterolateral versus nerve-sparing thoracotomy groups

\begin{tabular}{lcccc}
\hline \multicolumn{1}{c}{ Pain scores } & $\begin{array}{c}\text { Posterolateral } \\
(\mathbf{n}=\mathbf{4 5})\end{array}$ & $\begin{array}{c}\text { Nerve- sparing } \\
(\mathbf{n}=\mathbf{4 5})\end{array}$ & $\begin{array}{c}\text { Difference } \\
(\mathbf{9 9} \% \mathbf{C I})\end{array}$ & $\boldsymbol{P}$ value \\
\hline Worst pain score in first 3 postoperative d* ${ }^{*}$ & $3.83( \pm 1.3)$ & $3.71( \pm 1.6)$ & $0.12(-0.7,+0.9)$ & .70 \\
Average pain score in first 3 postoperative d* & $1.85( \pm 0.9)$ & $1.77( \pm 1.0)$ & $0.08(-0.4,+0.6)$ & .69 \\
Morphine requirement in first 3 postoperative d (mg/kg bodyweight)* & $1.40( \pm 0.6)$ & $1.45( \pm 0.7)$ & $-0.05(-0.4,+0.3)$ & .73 \\
Worst pain score at 10 to 14 d postoperatively* & $2.72( \pm 4.0)$ & $2.91( \pm 4.2)$ & $-0.19(-2.5,+2.1)$ & .83 \\
Average pain score at 10 to 14 d postoperatively* & $0.97( \pm 1.5)$ & $0.70( \pm 1.3)$ & $0.26(-0.5,+1.0)$ & .38 \\
No. of patients with chronic pain & $18 / 39(46.1 \%)$ & $17 / 41(41.2 \%)$ & $4.7 \%(-22.8,+30.7)$ & .73 \\
\hline
\end{tabular}

$C I$, Confidence interval. *Values are mean \pm standard deviation.

methodological issues, such as lack of patient (and more important, assessor) blinding, exclusion of large number of patients from final analysis, and nonstandard control arm.

Studies have also looked at the combination of nervepreservation techniques. Wu and colleagues ${ }^{13}$ randomized 80 patients undergoing thoracotomy to receive intercostal muscle flap with intracostal sutures or intracostal sutures alone. They found no difference in the incidence of chronic pain between the groups. Allama ${ }^{17}$ randomized 120 patients to have intercostal muscle flap with intracostal sutures or standard pericostal sutures. Although pain scores were lower in the intervention group at 1 month after surgery, there was no difference at 3 or 6 months. However, many of these studies with "positive" results had multiple concurrent comparisons, thereby considerably increasing the possibility of false-positive results. A review summarizing these studies ${ }^{32}$ has concluded that "techniques offering some form of protection to the intercostal nerve (such as intracostal sutures or the use of an intercostal muscle flap) are associated with significantly reduced postoperative pain and analgesic consumption, even up to 12 months after surgery." The most important criticism of these studies probably is the lack of patient and assessor blinding, which is critical while evaluating a subjective end point like postoperative pain.

TABLE 3. Postoperative complications

\begin{tabular}{lcc}
\hline \multicolumn{1}{c}{ Complications } & $\begin{array}{c}\text { Posterolateral } \\
(\mathbf{n}=\mathbf{4 5})\end{array}$ & $\begin{array}{c}\text { Nerve-sparing } \\
(\mathbf{n}=\mathbf{4 5})\end{array}$ \\
\hline Pulmonary complications & $4(9 \%)$ & $3(7 \%)$ \\
Prolonged ICU stay* & $3(7 \%)$ & $2(4 \%)$ \\
Major wound infection $\dagger$ & $2(4 \%)$ & 0 \\
Reexploration & $1(2 \%)$ & $1(2 \%)$ \\
$\begin{array}{l}\text { Median hospital stay in days } \\
\quad \text { with IQR) }\end{array}$ & $6(5-8)$ & $5(4-7)$ \\
Readmissions & $2(4 \%)$ & 0 \\
Postoperative death $\ddagger$ & $2(4 \%)$ & $1(2 \%)$ \\
\hline
\end{tabular}

Data are expressed as actual numbers (with percentages) for categoric data. ICU, Intensive care unit; $I Q R$, interquartile range. *Prolonged intensive care unit stay was defined as more than 24 hours after surgery. $\dagger$ Major wound infection was defined as Clavien-Dindo grade 3 and above. †़Postoperative mortality was calculated up to 30 days or in-hospital, whichever was later.
In trials comparing surgical techniques, it is often impossible to blind the surgeon to the treatment arm, which might introduce bias and dilute the validity of the study. The strength of our study is that despite the absence of blinding of the surgeon, we eliminated bias by randomization, allocation concealment, and blinding participants and assessors. Despite having numerous end points, we ensured that statistical adjustments were made to avoid the possibility of a Type 1 error. The results of our study are likely to be fairly generalizable because the eligibility criteria were not stringent and reflected a real-life scenario. However, the generalizability to populations with a higher body mass index cannot be assumed from our study.

\section{Study Limitations}

One of the limitations of our study is that the pain outcome assessments were limited to questionnaires that relied on patient reporting and did not involve an objective assessment of specific areas of allodynia or hyperesthesia. However, because the focus of our study was to compare the incidence of pain as a patient-reported outcome in both the groups and not to characterize the type of pain, we did not assess the nature of the pain. Another limitation of our study is the relatively small number of patients studied; however, the numbers were estimated on the basis of a formal sample size calculation based on a minimum clinically relevant difference in postoperative pain and with stringent levels of type 1 and 2 errors, including adjusting for multiple comparisons with a conservative Bonferroni correction. The only way we could have had a larger sample size would have been to further decrease the expected difference in pain scores, which would have made the question clinically irrelevant. Our study recorded pain scores only in the first 3 days, between 10 and 14 days and 6 months postoperatively because these are expected to reasonably capture differences in both acute and chronic PTP; differences in pain at other timepoints cannot be ruled out.

\section{CONCLUSIONS}

Our results show that protection of the intercostal nerve alone during thoracotomy does not affect acute or chronic 
PTP. Postoperative pain is possibly multifactorial and depends on the site of the surgical incision, disruption of the intercostal nerves, inflammation of the chest wall structures adjacent to the incision, pulmonary parenchyma or pleura, and thoracostomy drainage tubes; therefore, modifying only the operative strategy may not help in reducing pain. Multidisciplinary management of thoracotomy pain incorporating surgical, anesthetic, and analgesic techniques is probably needed, including the optimal use of epidural catheters, intercostal nerve blocks, paravertebral blocks, and PCA. ${ }^{33,34}$

\section{Conflict of Interest Statement}

Authors have nothing to disclose with regard to commercial support.

\section{References}

1. Lilienthal H. IV. The first case of thoracotomy in a human being under anaesthesia by intratracheal insufflation. Ann Surg. 1910;52:30-3.

2. Heitmiller RF. Thoracic incisions. Ann Thorac Surg. 1988;46:601.

3. Athanassiadi K, Kakaris S, Theakos N, Skottis I. Muscle-sparing versus posterolateral thoracotomy: a prospective study. Eur J Cardiothorac Surg. 2007:31:496-9.

4. Rogers ML, Duffy JP. Surgical aspects of chronic post-thoracotomy pain. Eur J Cardiothorac Surg. 2000;18:711-6.

5. Gerner P. Postthoracotomy pain management problems. Anesthesiol Clin. 2008; 26:355-67.

6. Merskey H, Bogduk H. Classification of chronic pain. In: Merskey H, Bogduk H, eds. Descriptions of Chronic Pain Syndromes and Definitions of Pain Terms. 2nd ed. Seattle, WA: IASP Press; 1994:143-4.

7. Pertunnen K, Tasmuth T, Kalso E. Chronic pain after thoracic surgery: a followup study. Acta Anaesthesiol Scand. 1999;43:563-7.

8. Katz J, Jackson M, Kavanagh BP, Sandler AN. Acute pain after thoracotomy predicts long-term post-thoracotomy pain. Clin J Pain. 1996;12:50-5.

9. Rogers ML, Henderson L, Mahajan RP, Duffy JP. Preliminary findings in the neurophysiological assessment of intercostal nerve injury during thoracotomy. Eur J Cardiothorac Surg. 2002;21:298-301.

10. Moorjani N, Zhao F, Tian Y, Liang C, Kaluba J, Maiwand MO. Effects of cryoanalgesia on post-thoracotomy pain and on the structure of intercostal nerves: a human prospective randomized trial and a histological study. Eur J Cardiothorac Surg. 2001;20:502-7.

11. Buvanendran A, Kroin JS, Kerns JM, Nagalla SN, Tuman KJ. Characterization of a new animal model for evaluation of persistent postthoracotomy pain. Anesth Analg. 2004;99:1453-60.

12. Marchetti-Filho MA, Leão LE, Costa-Junior Ada S. The role of intercostal nerve preservation in acute pain control after thoracotomy. J Bras Pneumol. 2014;40: 164-70.

13. Wu N, Yan S, Wang X, Lv C, Wang J, Zheng Q, et al. A prospective, single-blind randomised study on the effect of intercostal nerve protection on early postthoracotomy pain relief. Eur J Cardiothorac Surg. 2010;37:840-5.

14. Cerfolio RJ, Bryant AS, Maniscalco LM. A nondivided intercostal muscle flap further reduces pain of thoracotomy: a prospective randomized trial. Ann Thorac Surg. 2008;85:1901-6.
15. Cerfolio RJ, Bryant AS, Patel B, Bartolucci AA. Intercostal muscle flap reduces the pain of thoracotomy: a prospective randomized trial. J Thorac Cardiovasc Surg. 2005; 130:987-93.

16. Cerfolio RJ, Price TN, Bryant AS, Sale Bass C, Bartolucci AA. Intracostal sutures decrease the pain of thoracotomy. Ann Thorac Surg. 2003;76:407-11.

17. Allama AM. Intercostal muscle flap for decreasing pain after thoracotomy: a prospective randomized trial. Ann Thorac Surg. 2010;89:195-9.

18. Bethencourt DM, Holmes EC. Muscle-sparing posterolateral thoracotomy. Ann Thorac Surg. 1988;45:337-9.

19. Landreneau RJ, Pigula F, Luketich JD, Keenan RJ, Bartley S, Fetterman LS, et al. Acute and chronic morbidity differences between muscle-sparing and standard lateral thoracotomies. J Thorac Cardiovasc Surg. 1996;112:1346-50.

20. Hazelrigg SR, Landreneau RJ, Boley TM, Priesmeyer M, Schmaltz RA, Nawarawong W, et al. The effect of muscle sparing versus standard posterolateral thoracotomy on pulmonary function, muscle strength, and postoperative pain. $J$ Thorac Cardiovasc Surg. 1991;101:394-400.

21. Nomori H, Horio H, Suemasu K. Anterior limited thoracotomy with intrathoracic illumination for lung cancer: its advantages over anteroaxillary and posterolateral thoracotomy. Chest. 1999;115:874-80.

22. Nomori H, Horio H, Fuyuno G, Kobayashi R. Non-serratus-sparing anteroaxillary thoracotomy with disconnection of anterior rib cartilage. Improvement in postoperative pulmonary function and pain in comparison to posterolateral thoracotomy. Chest. 1997;111:572-6.

23. Landreneau RJ, Mack MJ, Hazelrigg ST, Dowling RD, Acuff TE, Magee MJ, et al. Video-assisted thoracic surgery: basic technical concepts and intercostal approach strategies. Ann Thorac Surg. 1992;54:800-7.

24. Miller JI, Hatcher CR. Thoracoscopy: a useful tool in the diagnosis of thoracic disease. Ann Thorac Surg. 1978;26:68-72.

25. Richardson J, Sabanathan S. Pain management in video assisted thoracic surgery: evaluation of localised partial rib resection. J Cardiovasc Surg. 1995;36:505-9.

26. Kirby TJ, Mack MJ, Landreneau RJ, Rice TW. Lobectomy-video-assisted thoracic surgery versus muscle-sparing thoracotomy. A randomized trial. J Thorac Cardiovasc Surg. 1995;109:997-1001.

27. Furrer M, Rechsteiner R, Eigenmann V, Signer C, Althaus U, Ris HB. Thoracotomy and thoracoscopy: postoperative pulmonary function, pain and chest wall complaints. Eur J Cardiothorac Surg. 1997;12:82-7.

28. Landreneau RJ, Mack MJ, Hazelrigg SR, Naunheim K, Dowling RD, Ritter P, et al. Prevalence of chronic pain after pulmonary resection by thoracotomy or video-assisted thoracic surgery. J Thorac Cardiovasc Surg. 1994;107:1079-85.

29. Yim AP. Video-assisted thoracic lung surgery: is there a barrier to widespread adoption? Ann Thorac Surg. 2010;89:S2112-3.

30. Carrott PW Jr, Jones DR. Teaching video-assisted thoracic surgery (VATS) lobectomy. J Thorac Dis. 2013;5:S207-11.

31. Bayram AS, Ozcan M, Kaya FN, Gebitekin C. Rib approximation without intercostal nerve compression reduces post-thoracotomy pain: a prospective randomized study. Eur J Cardiothorac Surg. 2011;39:570-4.

32. Visagan R, McCormack DJ, Shipolini AR, Jarral OA. Are intracostal sutures better than pericostal sutures for closing a thoracotomy? Interact Cardiovasc Thorac Surg. 2012;14:807-15.

33. Raveglia F, Rizzi A, Leporati A, Di Mauro P, Cioffi U, Baisi A. Analgesia in patients undergoing thoracotomy: epidural versus paravertebral technique. A randomized, double-blind, prospective study. J Thorac Cardiovasc Surg. 2014; 147:469-73.

34. Wheatley GH III, Rosenbaum DH, Paul MC, Dine AP, Wait MA, Meyer DM, et al. Improved pain management outcomes with continuous infusion of a local anesthetic after thoracotomy. J Thorac Cardiovasc Surg. 2005;130:464-8.

Key Words: nerve sparing, posterolateral, thoracotomy 